Document downloaded from:

http://hdl.handle.net/10251/64953

This paper must be cited as:

Serrano Cruz, JR.; Olmeda González, PC.; Arnau Martínez, FJ.; Dombrovsky, A.; Smith, L. (2015). Turbocharger heat transfer and mechanical losses influence in predicting engines performance by using one-dimensional simulation codes. Energy. 86:204-218. doi:10.1016/j.energy.2015.03.130.

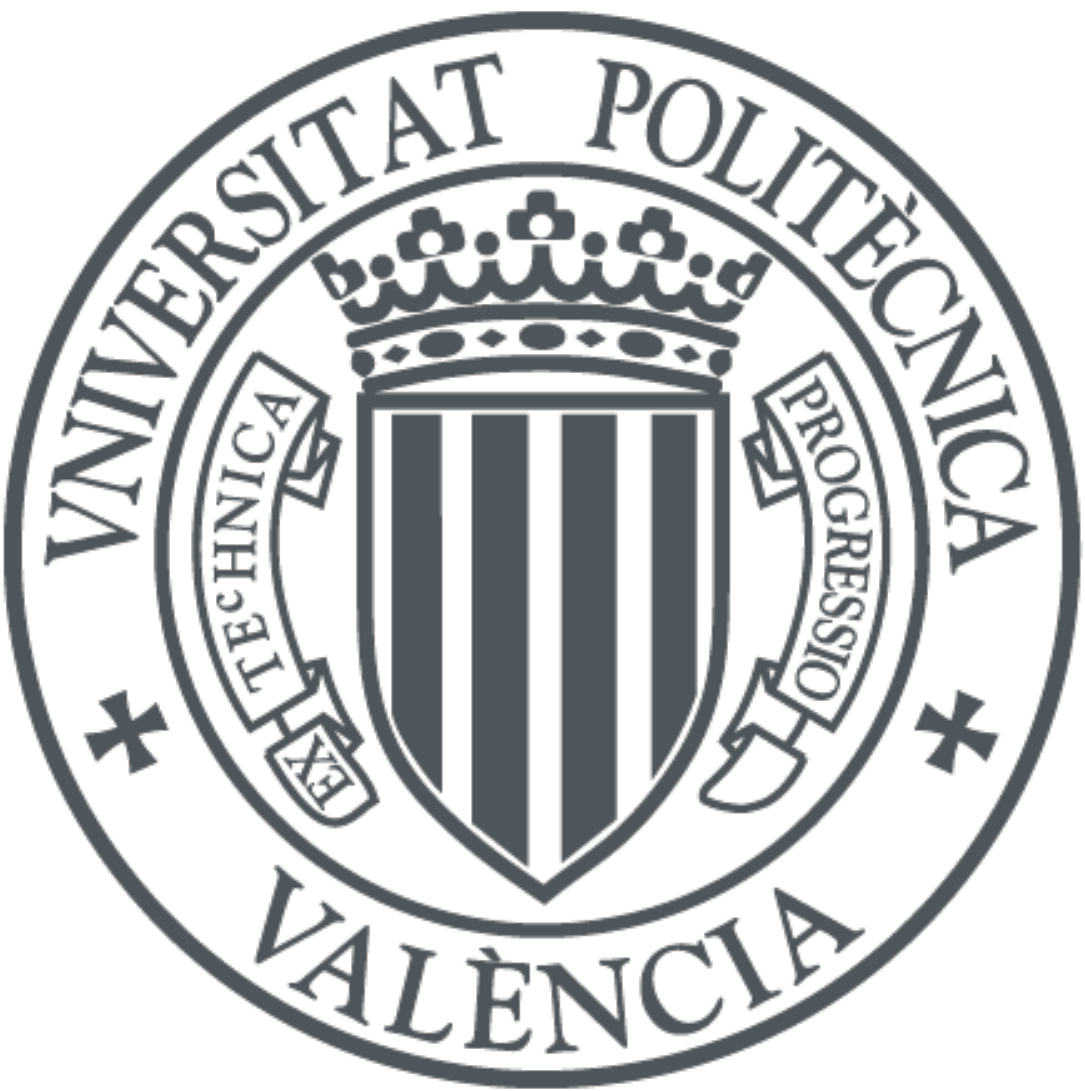

The final publication is available at

http://dx.doi.org/10.1016/j.energy.2015.03.130

Copyright Elsevier

Additional Information 


\title{
Turbocharger heat transfer and mechanical losses influence in predicting engines performance by using one-dimensional simulation codes
}

\author{
José Ramón Serrano, Pablo Olmeda*, Francisco J. Arnau, Artem Dombrovsky \\ CMT-Motores Térmicos, Universitat Politècnica de València, Camino de Vera s/n. 46022 \\ València, Spain \\ Les Smith \\ Jaguar Cars Limited, JLR Powertrain Analysis, Abbey Road, Whitley, Coventry, CV3 4LF, \\ $U K$
}

\begin{abstract}
The exhaust energy can represent up to $40 \%$ of the fuel chemical energy in turbocharged internal combustion engines. In order to calculate properly the available energy of the exhaust gases, a critical parameter is the temperature downstream the turbine. The prediction of this temperature will also benefit the two-stage turbochargers and after-treatment modelling that affects brake specific fuel consumption, exhaust gases emissions and the scavenging process.

In this paper, turbocharger heat transfer losses have been modelled using a lumped capacitance model coupled with one-dimensional whole-engine simulation software. The data from the simulations of a turbocharged Diesel engine, with and without the turbocharger heat transfer model, have been compared with experimental measurements performed in an engine test bench. The analysis is focused on studying the influence in turbocharger outlet temperatures and predicting the engine performance. The main result of the study is the improvement in the prediction of both compressor and turbine outlet temperatures (up to an improvement of $70 \mathrm{~K}$ ). The results from the model allow analysing how
\end{abstract}

\footnotetext{
* Corresponding author

Email address: pabolgon@mot.upv.es (Pablo Olmeda)

URL: www.cmt.upv.es (Pablo Olmeda)
}

Preprint submitted to Energy

March 17, 2015 
heat transfer losses are split in the turbocharger and quantifying the importance of heat transfer phenomena in turbocharger efficiency, at full load conditions and as a function of engine speed.

Keywords: internal combustion engine, turbocharger, heat transfer, one-dimensional model 


\section{Nomenclature}

\begin{tabular}{|c|c|c|}
\hline$a$ & Sensor uncertainty & - \\
\hline$c_{p}$ & Specific heat capacity & $\mathrm{J} \cdot \mathrm{kg}^{-1} \cdot \mathrm{K}^{-1}$ \\
\hline$h$ & Specific enthalpy & $\mathrm{J} \cdot \mathrm{kg}^{-1}$ \\
\hline$K$ & Turbocharger speed constant & $\mathrm{rpm} / \mathrm{W}$ \\
\hline$p$ & Pressure & $\mathrm{Pa}$ \\
\hline$s$ & Specific entropy & $\mathrm{J} \cdot \mathrm{kg}^{-1} \cdot \mathrm{K}^{-1}$ \\
\hline$n$ & Number of measurements & - \\
\hline$N$ & Turbocharger speed & $\mathrm{rpm}$ \\
\hline$T$ & Temperature & $\mathrm{K}$ \\
\hline$\dot{m}$ & Mass flow & $\mathrm{kg} \cdot \mathrm{s}^{-1}$ \\
\hline$\dot{Q}$ & Heat flow & $\mathrm{W}$ \\
\hline$u$ & Standard deviation & - \\
\hline$\dot{W}$ & Mechanical power & $\mathrm{W}$ \\
\hline$\dot{W}^{\prime}$ & Mechanical and heat power & $\mathrm{W}$ \\
\hline \multicolumn{3}{|c|}{ Greek symbols } \\
\hline$\eta$ & Efficiency & - \\
\hline$\Delta$ & Increment or drop & - \\
\hline \multicolumn{3}{|c|}{ Subscripts and superscripts } \\
\hline 0 & Total conditions & \\
\hline 1 & Compressor inlet & \\
\hline 2 & Compressor outlet & \\
\hline 3 & Turbine inlet & \\
\hline 4 & Turbine outlet & \\
\hline$a, a d i a b$. & Adiabatic conditions & \\
\hline$c$ & Refers to compressor & \\
\hline$C$ & Compressor node & \\
\hline$d i a b$. & Diabatic conditions & \\
\hline$G A S$ & Gas node & \\
\hline$t$ & Refers to turbine & \\
\hline
\end{tabular}




$\begin{array}{ll}T & \text { Turbine node } \\ H 1 & \text { Turbine housing node } \\ H 2 & \text { Central housing node } \\ H 3 & \text { Compressor housing node } \\ W & \text { Water node } \\ I C & \text { Compressor inlet } \\ O C & \text { Compressor outlet } \\ O C_{s} & \text { Isentropic compressor outlet } \\ I T_{1} & \text { Adiabatic turbine inlet } \\ O T & \text { Turbine outlet } \\ O T_{s} & \text { Isentropic turbine outlet } \\ s & \text { Isentropic } \\ T G & \text { Refers to turbocharger } \\ m e c h & \text { Refers to mechanical losses }\end{array}$

Abbreviations

$\mathrm{AC}$

Alternating current

BSFC

Brake specific fuel consumption

CALMEC $^{\mathrm{TM}}$

Combustion diagnosis tool

CFD

Computational fluid dynamics

COT

Compressor outlet temperature

ECU

Engine control unit

EGR

Exhaust gas recirculation

ETE

Effective turbine efficiency

EVO

Exhaust valve opening

HT\&ML Heat transfer and mechanical losses model

ORC Organic Rankine Cycle

TOT Turbine outlet temperature

VGT Variable geometry turbine 


\section{Introduction}

The research on internal combustion engines is currently focused on energy optimisation and the reduction of fuel consumption and pollutant emissions. Different strategies to fulfil these objectives have been studied. Engine down5 sizing combined with a high level of turbocharging is one of these strategies [1]. Moreover, turbocharging affects other engine systems such as EGR [2], cooling and combustion; all of them related both with engine BSFC and engine emissions. In addition, the phenomena taking place internally to the turbocharger affect engine performance [3]. Turbocharger heat transfer is one of these phenomena. In order to estimate the heat fluxes in a turbocharger, working coupled to the engine, several approximations proposed by different authors can be employed, as described below.

Some authors have studied the phenomena experimentally, both in a gas stand 4] and in an engine test bench [5, while other studies are theoretical

15 6]. The gas stand tests aim to decouple the turbocharger phenomena from the ones associated to the engine. The engine test bench experiments represent the closest approximation to real vehicle operation conditions. An important effort has been made by some authors [7] in analysing different heat transfer conditions in the turbocharger on engine operation. These studies conclude that the importance of heat transfer phenomena in the overall power exchange inside the turbocharger can be significant at low and medium turbocharger speeds.

Other authors 8 , have performed CFD (Computational Fluid Dynamics) studies in order to better understand the phenomena and their implications. These studies show the relevant heat transfer paths and their magnitude. However, due to computational limitations, this approach cannot be used if a whole engine has to be modelled.

The experimental approach is closer to the real application but it is inefficient in engine design because a test campaign of prohibitive economical cost would be needed. The CFD approach is able to save part of these costs but so at high temporal costs and it cannot be used in a whole engine model (the 
computational cost would be prohibitive). Between both options, a 1D modelling codes such as GT-Suite can be used, which are extensively used by engine manufacturers in design and research. This approach makes possible the prediction of variables related to both the engine and the turbocharger, crucial when overall conclusions are needed. Some authors have used this methodology in predicting different variables related to the engine and turbocharger system comparing with experimental results, and considering different approaches for the turbocharger 9 .

The present work tries to clarify the strong debate about the influence of turbocharger heat transfer and mechanical losses (HT\&ML, from now on) models on engine performance prediction. Some authors have performed experimental measurements in gas stand concluding that the effect of turbocharger heat transfer is irrelevant compared to turbocharger mechanical power at high engine loads [10]. However, more recent studies [11] show that heat transfer in 45 the turbine always represent an important part of its enthalpy change, being more relevant in the low torque region. Some authors 12 have measured turbocharger performance in an engine test bench concluding that at high engine speeds and loads the deviation between adiabatic and non-adiabatic compressor efficiency is small. Nevertheless, other authors [13] have pointed that at 50 higher powers the distribution of heat transfer during compression process has important effects. It is widely accepted that the influence of HT\&ML models is important at part loads and at transient operation [14]. However, neither studies quantifying the influence of these models on engine parameters nor studies indicating the engine parameters affected are found in the literature. In the present work the importance of these models on full load simulations is shown.

In order to clarify this controversy, a simple lumped model able to predict heat transfer and mechanical losses phenomena in turbochargers is used, coupled with a complete engine model built in GT-Power. Engine full load conditions at different speeds have been simulated and compared with experimental re60 sults. Experimental tasks have been described in the first place; focusing on the description of test rig and equipment used; the different turbochargers and 
engines that have been tested; the description of the testing methodology and the results of the tests. The second part of the paper is focused on the modelling work, starting with a brief description of the HT\&ML model used, followed by a description of the engine model in GT-Power, and finishing with a description of the performed simulations. Then, a discussion of the obtained results with the different models and their comparison with experimental data is presented. Finally, the main conclusions of the work are summarised.

\section{Experimental work}

The experimental tasks of this work have been performed in an engine test bench using two different turbochargers (with and without water cooling) coupled to a 2 litres engine, but emulating 1.6 litres engine for the non water-cooled turbocharger (downspeeding).

\subsection{Engine test bench}

A schematic of the engine test bench is presented in Figure1. It is a standard engine test rig, designed for the study of internal combustion engines up to 200 $\mathrm{kW}$ of power. The facility is assembled to control and evaluate the engine performance in steady and transient conditions. The most important devices of the engine test bench are:

- AC-Dynamometer, variable frequency and high response.

- High frequency analogical data acquisition system.

- Test room control device and data acquisition system.

- Continuous smoke measurement device.

- Control strategies design hardware.

- Air flow measurement system (hot-wire anemometer).

- Transient fuel-flow measurement balance. 


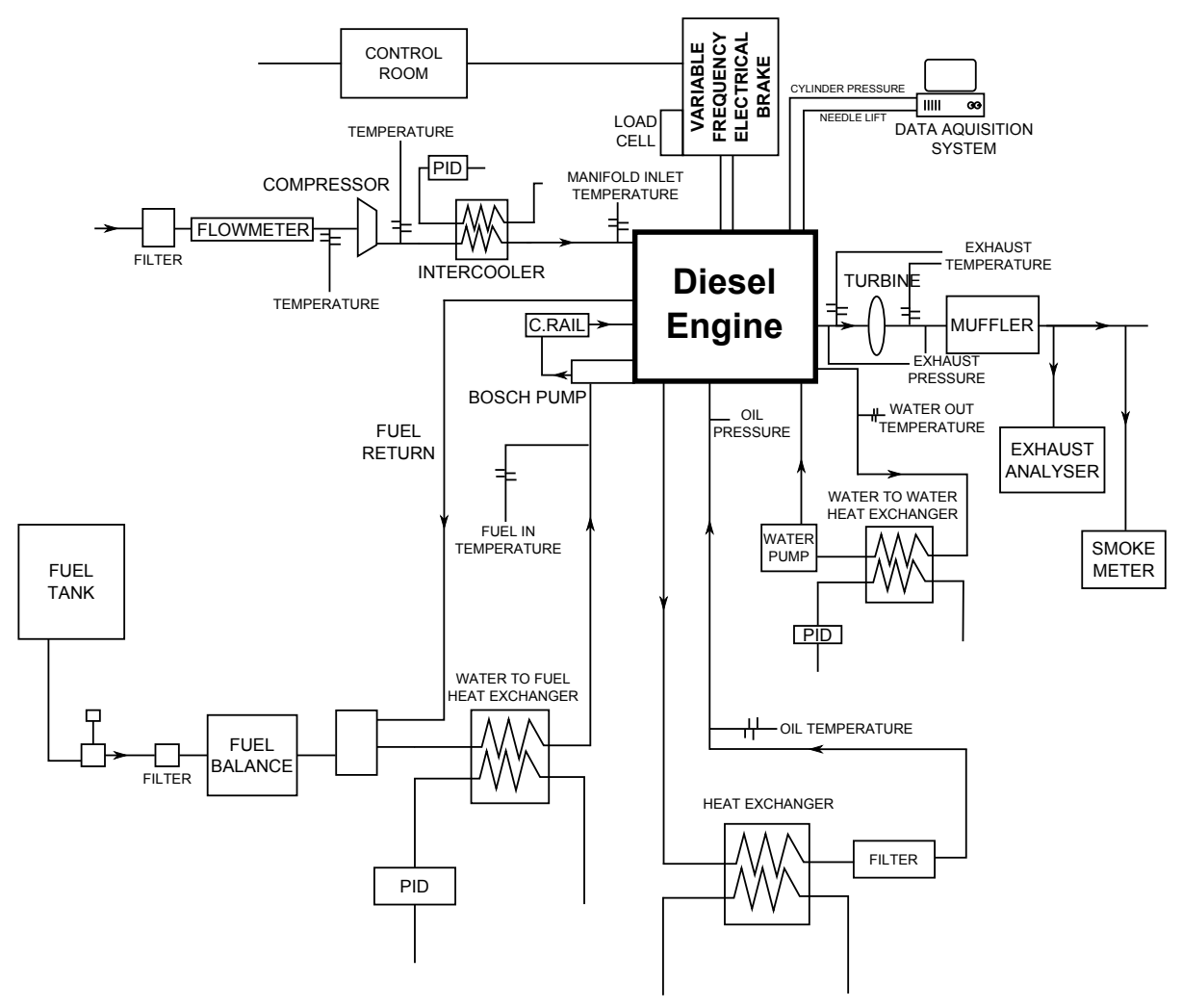

Figure 1: Engine test bench layout

- Piezoelectric and piezoresistive cooled pressure transducer.

- Exhaust gas analyser.

- Thermocouples and Thermoresistances.

In an engine test bench the measurement conditions of the turbocharger offer less freedom than in a gas stand, although the test conditions are closer to the real operation of the turbocharger.

For the measurements of current work the uncertainty estimation was evaluated by using a statistical analysis from manufacturers data as it has been proposed in [15]. In Table 1 the uncertainty of the sensors is shown. The uncertainty due to the inaccuracy of each sensor is computed assuming uniform rectangular distribution of probability [16. Equation 1 is used in this case. 
Table 1: Characteristics of the main sensors

\begin{tabular}{|c|c|c|}
\hline Variable & Sensor & Range / Uncertainty \\
\hline Gas Pressure & Piezoresistive & {$[0-5] \pm 0.025$ bar } \\
\hline Gas, and wall Temp. & K-type Therm. & {$[-200-+1200] \pm 2.2^{\circ} \mathrm{C}$} \\
\hline Gas Mass Flow & Hot wire & {$[0-720] \pm 0.72 \mathrm{~kg} / \mathrm{h}$} \\
\hline Oil Pressure & Piezoresistive & {$[0-6] \pm 0.025$ bar } \\
\hline Oil Temperature & RTD & {$[-200-+650] \pm 0.15^{\circ} \mathrm{C}$} \\
\hline Oil Flow & Coriolis & {$[0-100] \mathrm{kg} / \mathrm{h} \pm 0.1 \%$} \\
\hline Coolant Pressure & Piezoresistive & {$[0-6] \pm 0.025$ bar } \\
\hline Coolant Temperature & RTD & {$[-200-+650] \pm 0.15{ }^{\circ} \mathrm{C}$} \\
\hline Coolant Flow & Magnetic & {$[50-6000] \mathrm{kg} / \mathrm{h} \pm 0.1 \%$} \\
\hline Fuel Mass & Fuel Balance & {$[0-150] \mathrm{kg} / \mathrm{h} \pm 0.12 \%$} \\
\hline Crankshaft Angle & Angular Encoder & {$[1-20000] \mathrm{rpm}+0.02^{\circ}$} \\
\hline
\end{tabular}

Finally, the measurement uncertainty is calculated using Equation 2 which yield a maximum uncertainty in enthalpy drops measurements of $2 \%$.

$$
u_{c}=\sqrt{\sum_{i=1}^{k}\left(\frac{\partial f}{\partial x_{i}}\right)^{2} \cdot u^{2}\left(x_{i}\right)}
$$

\subsection{Turbochargers and engine characteristics}

Two different turbochargers have been tested on engine. The main difference between them is the presence of water cooling and their characteristics are described in Table 2. A 2.0 litres HSDI engine is used for both turbochargers. Its main technical characteristics are presented in Table 3 . Turbocharger T\#1 is the original one of this engine, while for T\#2 tests, downspeeding has been applied in order to avoid turbocharger overspeed. It means that engine speeds were adapted to emulate a 1.6 litre engine volumetric flow rate for the smaller 
turbocharger ( $\mathrm{T} \# 2)$. In this way full load engine points at different speeds have been measured for both turbochargers.

Table 2: Main characteristics of the employed turbochargers

\begin{tabular}{ccc}
\hline Parameter & T\#1 & T\#2 \\
\hline Turbine wheel diameter $[\mathrm{mm}]$ & 41 & 38 \\
Compressor wheel diameter $[\mathrm{mm}]$ & 49 & 46 \\
VGT & yes, vanes & yes, vanes \\
Water-cooling & yes & no \\
Matched to a characteristic engine displacement of $[l]$ & 2.0 & 1.6 \\
\hline
\end{tabular}

Table 3: Main characteristics of the employed engine

\begin{tabular}{cc}
\hline Parameter & Value \\
\hline Engine Displacement $\left[\mathrm{cm}^{3}\right]$ & 1997 \\
Bore $[\mathrm{mm}]$ & 85 \\
Stroke $[\mathrm{mm}]$ & 88 \\
Number of cylinders & 4 in line \\
Valves & 4 per cylinder \\
Compression ratio & 16 \\
\hline
\end{tabular}

\subsection{Engine full load tests}

Previously to the full load tests a set of different tests on the engine have been performed to characterise the valves flow coefficients and the combustion process in order to build an accurate 1D GT-Power engine model. Valves flow coefficients are important for calibrating the gas exchange process in the cylinder and to predict intake mass flow correctly using the model. The characterisation of the combustion process is necessary for a good estimation of the in-cylinder conditions at the exhaust valve opening which affects the available energy at 
the turbine inlet. This characterisation has been performed using instantaneous in-cylinder pressure signal from full load tests as will be described below.

Valves flow coefficients were obtained using a cold flow gas stand [17. The cylinder head was disassembled from the engine and set up in a gas stand where the flow coefficients of intake and exhaust valves have been obtained for direct and reverse flow. The measurements were performed modifying the valve lift. These tests provided curves for all valves that correlated flow coefficients with valve lift.

Combustion process was characterised using an in-house combustion diagnosis tool $\left(\right.$ CALMEC $^{\mathrm{TM}}$ ) [18, which is based on the measured instantaneous in-cylinder pressure and the characterization of some uncertainties [19. From this measurement and other parameters that define the engine working point, CALMEC $^{\mathrm{TM}}$ is able to determine the heat release law by using the first principle of thermodynamics. The main objective of this task is to provide enough information to predict the in-cylinder conditions at the exhaust valve opening and then the fluid thermal state at turbine inlet.

Obtained experimental results from engine tests will be shown and they will be further discussed when compared with modelling data.

\section{Modelling work}

The modelling work is divided in three parts. In the first part a HT\&ML model has been developed on the basis of previous works done by the authors and programmed as user function in a commercial code for engine simulations called GT-Power. Then, an engine model has been developed and validated in GT-Power environment. Finally, simulations with and without the HT\&ML model have been performed in order to analyse the benefits and drawbacks of this model in engine simulations.

\subsection{Turbocharger heat transfer and mechanical losses model}

145

The main objective of the HT\&ML model is the easiness to be used coupled with a general purpose models like GT-Power. For that reason, a 1D lumped 
model is chosen as described in [20] and presented in Figure 2, In the model, the turbocharger has been divided in five metal nodes: one for the turbine case, one for the compressor case and three for the bearing housing. The variables of this model have been computed using experimental data provided by tests performed in specific test rigs, saving the costs of engine bench tests. On one hand, the thermal properties of the turbocharger are calculated from measurements on a thermohydraulic test bench described in [21] and following the procedure explained in 22]. On the other hand, measurements in a hot flow gas stand allowed to obtain the correlations for both internal heat transfer 23 and external heat transfer [24]. In addition, in order to adapt a mathematical model for turbocharger mechanical losses as described in [25], adiabatic measurements from gas stand have been used. Therefore, using these models, the calculation of heat transfer and mechanical losses for any operating condition of the turbocharger in the engine is possible.

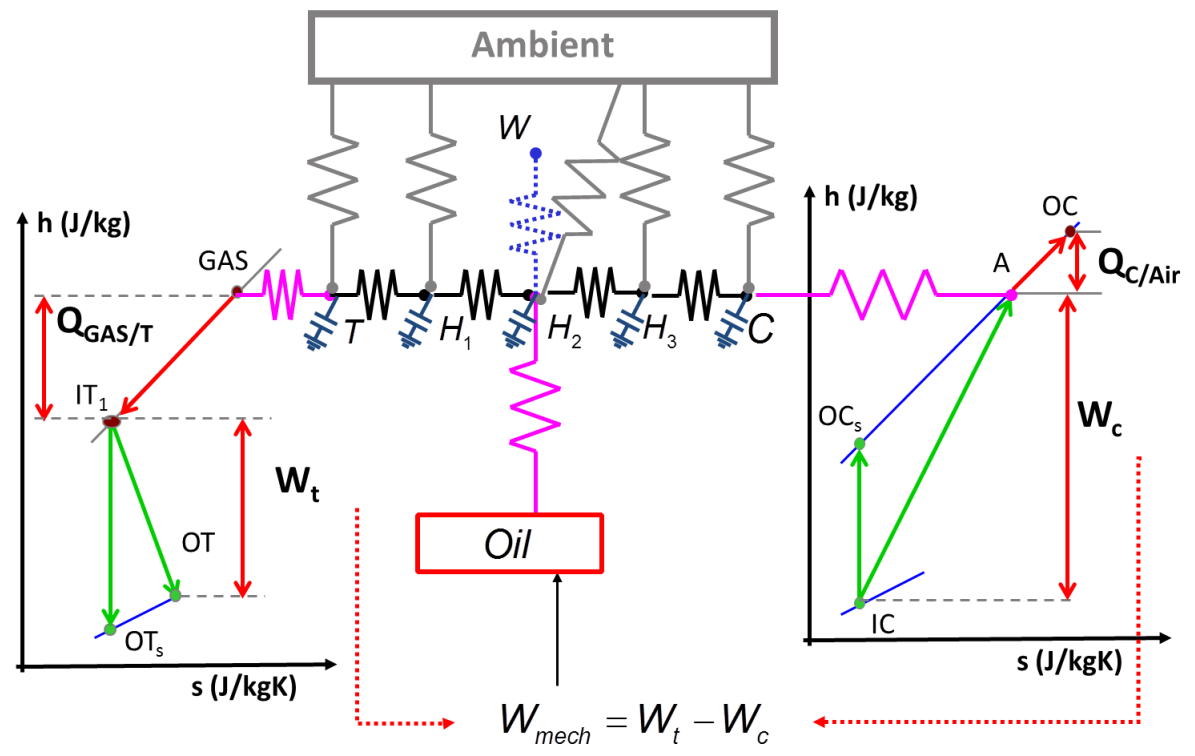

Figure 2: 1D lumped model

All the provided data make possible the correct computation of the model parameters in order to use it coupled with GT-Power, in a similar way to the work 


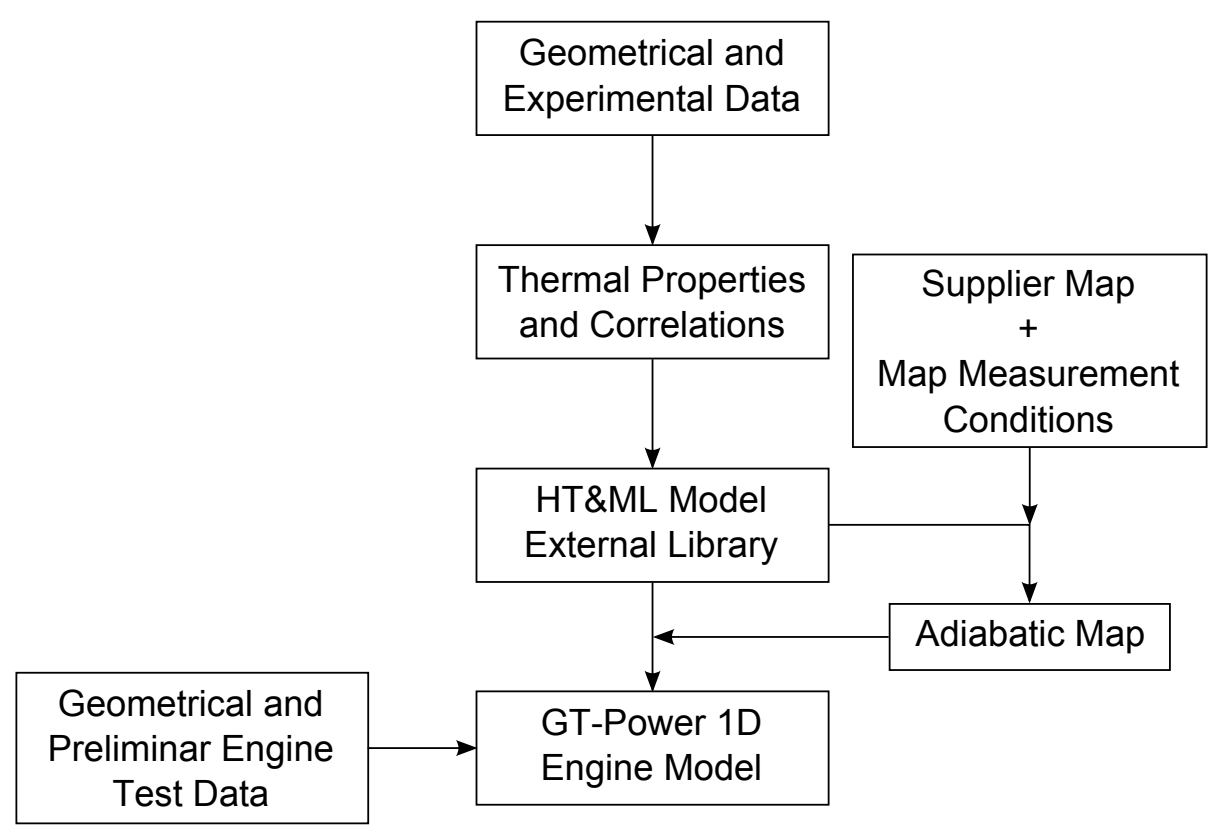

Figure 3: Modelling procedure

done in [26] in which only gas stand data have been analysed. The procedure is outlined in Figure 3, which shows that HT\&ML model is built on the basis of thermal properties and heat transfer correlations for convection. Those correlations have been obtained from test campaigns on both thermohydraulic test bench and gas stand and from turbocharger simple geometrical data (detailed geometry is not needed). The model for a given turbocharger is programmed in an external library for further use. It is important to take into account that the HT\&ML model coupled with the engine model uses adiabatic compressor and turbine performance maps. These maps can be obtained from direct adiabatic measurements or from supplier (or hot) maps using the HT\&ML in the inverse form, i.e. removing the heat from the measured hot map [23. For that inverse use additional information about map measurement conditions (temperatures, mass flows, etc.) is needed. Using the described arrangement, simulations in GT-Power can be performed taking into account the turbocharger heat transfer and mechanical losses model and using on engine test data for boundary 
conditions definition.

\subsection{Engine model}

The engine model was built in GT-Power using, among others, the data and tests mentioned in previous sections. A general scheme of the engine model in GT-Power is shown in Figure 4. The HT\&ML model has been introduced in the engine model acting on the compressor, turbine and shaft variables in order to take into account the heat transfer and mechanical losses phenomena in the turbocharger during the simulation.

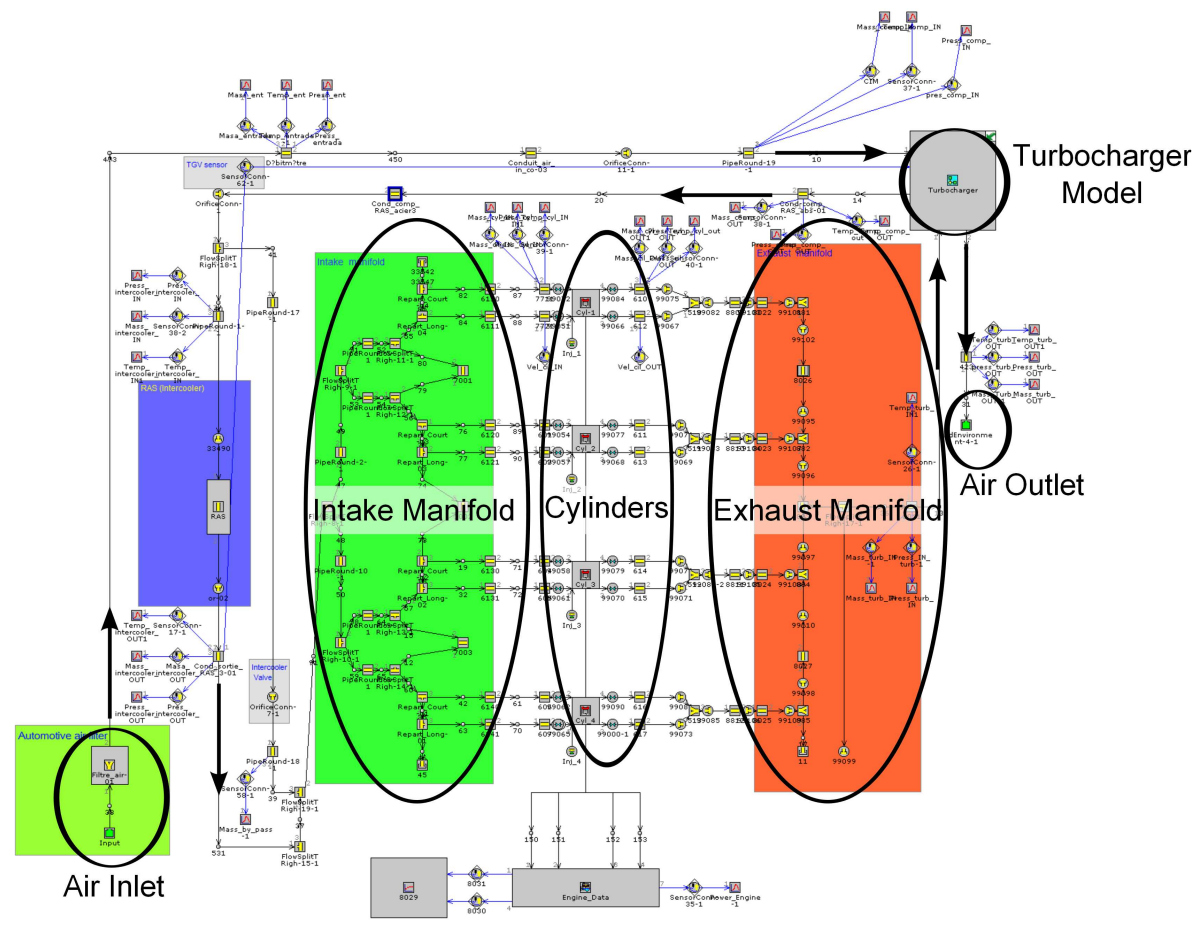

Figure 4: Engine Model in GT-Power

In order to assure correct turbine inlet conditions the in-cylinder instantaneous variables values provided by the model have been analysed. As it had been described in section 2.3 heat release laws obtained by an in-house combustion diagnosis tool $\left(\mathrm{CALMEC}^{\mathrm{TM}}\right)$ have been imposed in the cylinder, so GT- 


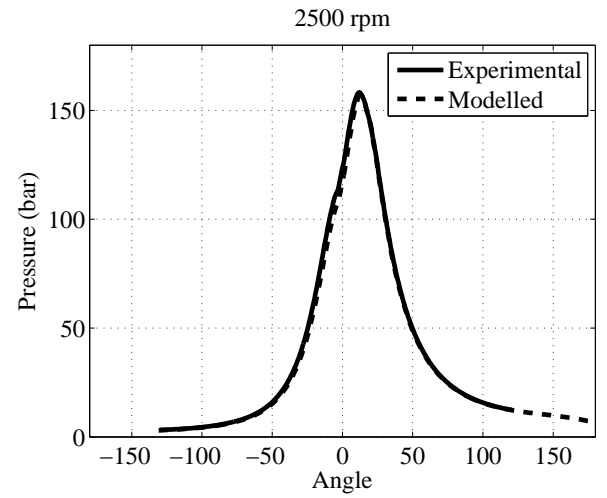

(a) Pressure

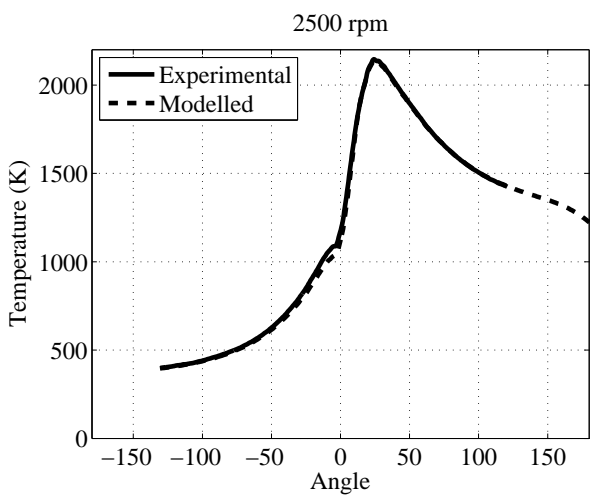

(b) Temperature

Figure 5: In-cylinder pressure and temperature for $\mathrm{T} \# 1$ at $2500 \mathrm{rpm}$ and full load (2.0 litres engine)

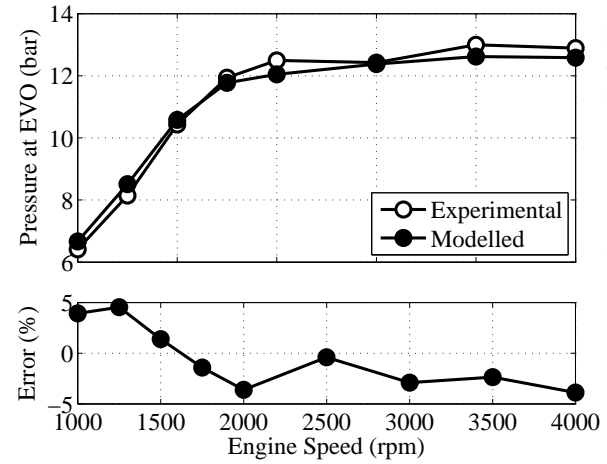

(a) Pressure

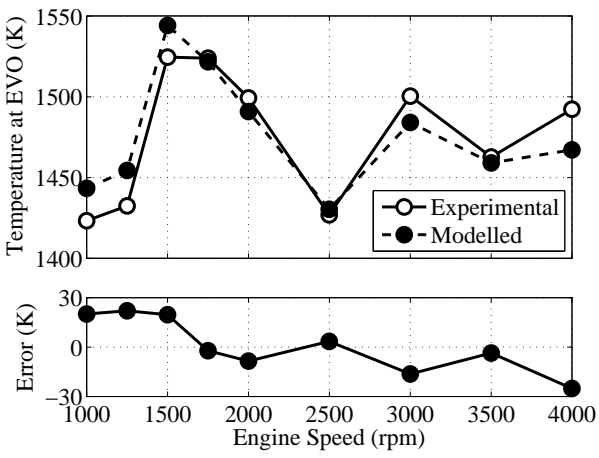

(b) Temperature

Figure 6: In-cylinder pressure and temperature at EVO for T\#1 (2.0 litres engine)

Power inbuilt heat release models have not been used. Moreover, in-cylinder heat transfer coefficients have been adjusted in order to meet in-cylinder measured values. In Figure 5 instantaneous in-cylinder pressure and temperature are shown comparing the modelled values with instantaneous experimental values for a given engine speed. The differences are small, a fact that validates in-cylinder heat transfer coefficients adjustment. It can be observed, in Figure 
6. that in-cylinder pressure at exhaust valve opening is also very similar for all the modelled engine speeds, being the errors within $\pm 5 \%$. The same holds for temperature, where errors are in the range of $\pm 20 K$, using the same set of in-cylinder heat transfer coefficients for all calculated engine speeds. Identical results from in-cylinder variables have been obtained using the HT\&ML or not (for that reason only one curve for modelled values is shown in Figures 5 and 6), meaning that in-cylinder conditions are not affected by turbocharger HT\&ML model in the modelled cases, what indicates that any difference in cylinder outlet variables (primary the turbine inlet temperature), cannot be caused by the use of HT\&ML model.

\subsection{Model results}

The simulations performed on the GT-Power engine model were made in full load conditions using two different configurations:

- Original GT-Power turbocharger model, using turbine and compressor maps measured in a gas stand at hot conditions which includes turbocharger friction losses in the effective turbine efficiency (ETE). That fact means that ETE, shown in Equation 3 is used as provided by the turbocharger manufacturer. This is the standard practice.

$$
\eta_{t, \text { map }}=E T E=\frac{\dot{m}_{c} \cdot c_{p, c} \cdot\left(T_{20}-T_{10}\right)}{\dot{m}_{t} \cdot c_{p, t} \cdot\left(T_{30}-T_{4 s}\right)}=\frac{\dot{W}_{c}+\dot{Q}_{C / A i r}}{\dot{W}_{t s}}
$$

- HT\&ML model programmed in GT-Power, using turbine and compressor adiabatic maps. This is the new approach that is intended to be evaluated.

The results of $\mathrm{T} \# 1$ will be represented versus the real engine speed. On the contrary, the results of the $\mathrm{T} \# 2$ will be plotted versus an emulated engine speed. For this last turbocharger, engine speed was lowered during the tests to keep adequate volumetric flow due to the use of a 2.0 litres engine instead of 1.6 litres engine, as it had been explained in section 2.2 The results of both configurations have been compared with experimental data from the tests described in section 2.3 


\subsubsection{Model prediction validation}

Figure 7 and Figure 8 compare the results of the models with the experimental data in torque and air mass flow. Good agreement has been achieved using both configurations (with and without HT\&ML model). As it can be observed, from the point of view of these two parameters, related with the engine behaviour, the differences between both configurations are insignificant.

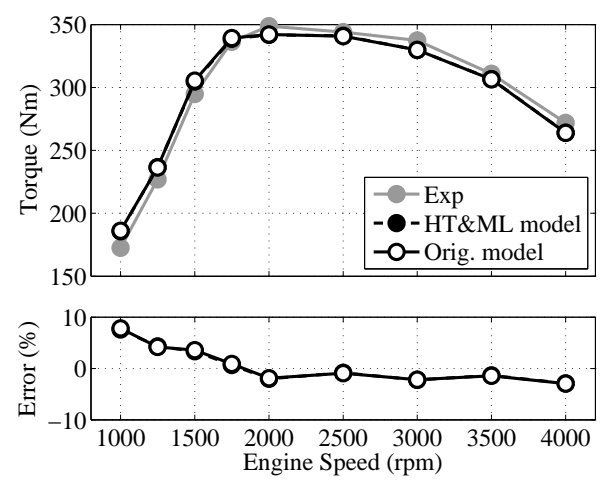

(a) Torque

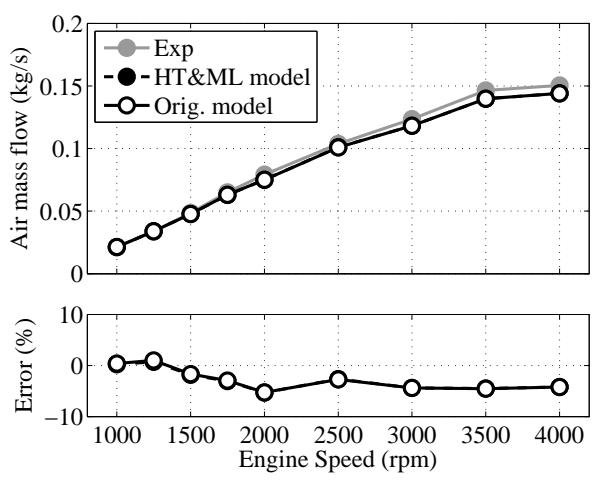

(b) Air mass flow

Figure 7: Engine variables T\#1. Actual 2.0 litres engine
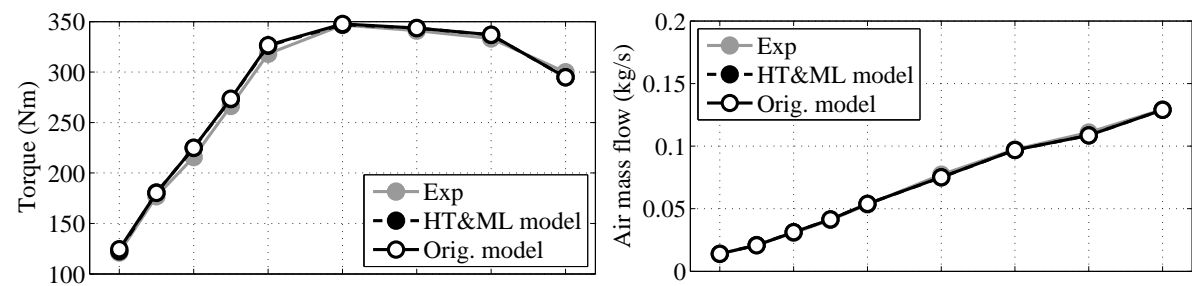

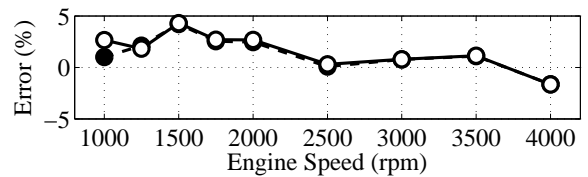

(a) Torque

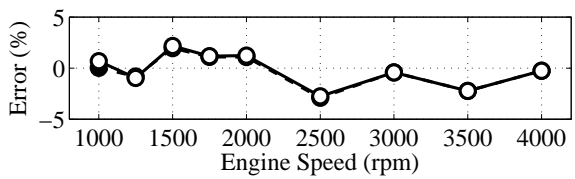

(b) Air mass flow

Figure 8: Engine variables T\#2. Emulated 1.6 litres engine

Figure 9 and Figure 10 show compressor parameters for both turbocharg- 

one, i.e. it does not include the effect of the heat transfer that will have to
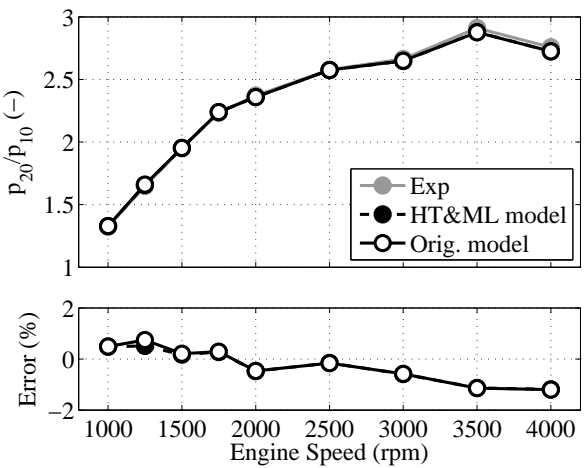

(a) Pressure ratio
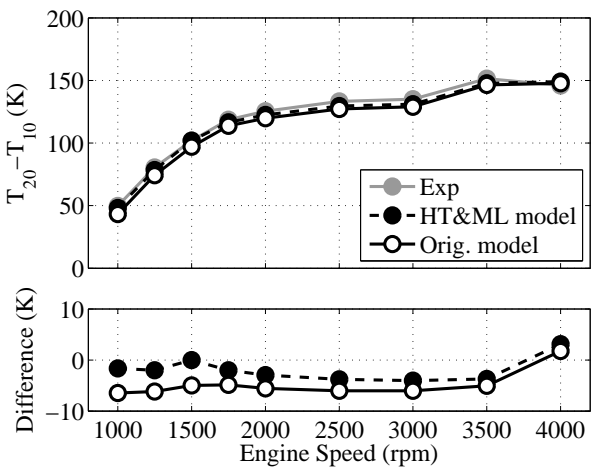

(b) Compressor $\Delta T$

Figure 9: T\#1 Compressor pressure ratio and temperature increment

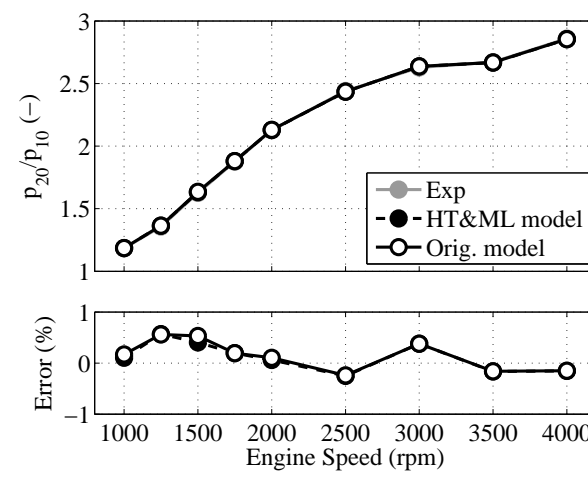

(a) Pressure ratio

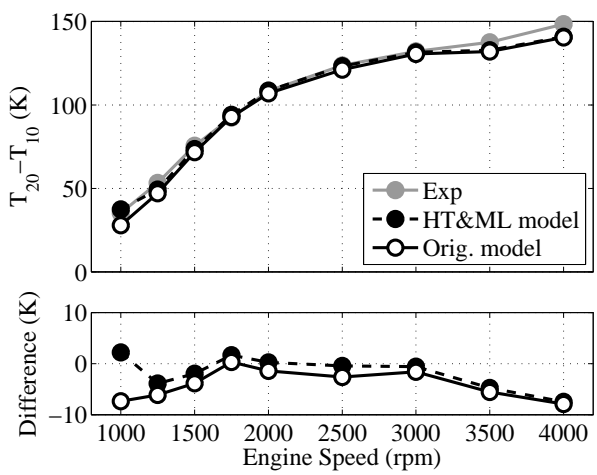

(b) Compressor $\Delta T$

Figure 10: T\#2 Compressor pressure ratio and temperature increment

be provided by the HT\&ML model. Pressure ratio against mass flow maps are 
identical with and without HT\&ML model [26] and the effect of heat transfer is reflected in the compressor efficiency [27] i.e. in the air temperature increment across the compressor. Compressor outlet temperature is related with the compression ratio (both cases have the same value) and the efficiency, so this parameter is affected by heat transfer and must be used properly. In the case of the original model the heat transfer effects are included in the map efficiency which is only valid when simulation conditions are similar to the conditions during map measurement. In the case of the new approach (using a HT\&ML model), the employed efficiencies are adiabatic, so point '20a' in Figure 11 can be obtained. Furthermore, heat transfer in the compressor is computed using HT\&ML model taking into account simulation conditions so adding that heat flow makes possible the calculation of the final COT (point '20' in Figure 11).

The definition of efficiencies in adiabatic and in hot (diabatic) maps are presented in Equations 4 and 5, where the temperature definitions are shown in Figure 11 .

$$
\begin{gathered}
\eta_{c, a d i a b .}=\frac{T_{20 s}-T_{10}}{T_{20 a}-T_{10}}=\frac{\dot{W}_{c s}}{\dot{W}_{c}} \\
\eta_{c, \text { diab. }}=\frac{T_{20 s}-T_{10}}{T_{20}-T_{10}}=\frac{\dot{W}_{c s}}{\dot{W}_{c}^{\prime}}=\frac{\dot{W}_{c s}}{\dot{W}_{c}+\dot{Q}_{C / A i r}}
\end{gathered}
$$

The hot map includes the effect of the heat transfer and mechanical losses in the turbocharger for the map measurement conditions. For this reason, the prediction of a model using hot maps, in principle, will be accurate if the conditions of turbine inlet temperature and oil inlet temperature are similar between the modelled and the experimental ones when the maps were measured. Since $T_{20}$ can be derived from the diabatic compressor efficiency $\left(\eta_{c, \text { diab. }}\right)$ by using Equation 5 .

The simulations of this paper for the original model use a hot map, where the map measurement temperatures were similar to those measured at full load engine conditions. If the map conditions were different, the measured diabatic 


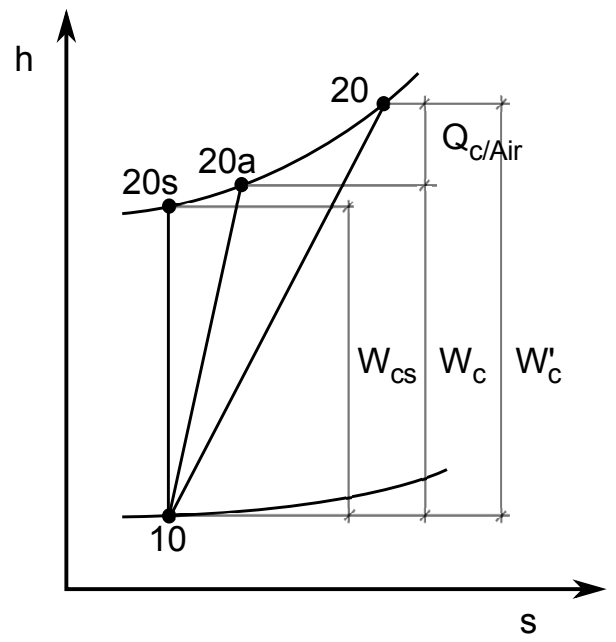

Figure 11: Enthalpy-entropy chart of the compression process

efficiency would be also different. Then compressor outlet temperature prediction would be worse than the results shown in Figures $9 \mathrm{~b}$ and $10 \mathrm{~b}$

On the contrary, HT\&ML model uses adiabatic map, i.e. considering that the air is only heated due to the compression process and the internal irreversibilities. The heat transfer model estimates the heat to or from the compressor $\left(\dot{Q}_{C / \text { Air }}\right)$ for each operating condition and this heat is added/removed at the compressor outlet as can be observed in Figures 2 and 11. So, the same $T_{20}$ is obtained in both cases: using a hot map measured with identical temperature conditions than in engine measurements and using the evolution given by $\eta_{c, d i a b}$. and using a two step evolution given by the efficiency $\eta_{c, a d i a b .}$ of an adiabatic map and the additional heat power $\left(\dot{Q}_{C / A i r}\right)$ of the HT\&ML. For this reason, the differences observed between the results obtained using the HT\&ML and those obtained with the original model are small. However, when the conditions of the map are not similar, HT\&ML would still give the same result while the original model may underpredict or overpredict COT.

In spite of this, HT\&ML model shows better results, specially at the low speed range (below $2000 \mathrm{rpm}$ ) as in Figure $9 \mathrm{~b}$ and $10 \mathrm{~b}$. It is due to the fact 280 that generally the heat transfer in the compressor is very small in comparison 
to the compressor power except for very low turbocharger speed, as it has been studied in [28. Despite of these small differences, up to $10 \mathrm{~K}$ improvement is observed using HT\&ML model which is more relevant for the higher power water cooled turbocharger $(\mathrm{T} \# 1)$.

Figure 12 and Figure 13 compare modelled pressure ratio and temperature drop at the turbine versus experimental data for both turbochargers. Once again, significant differences have not been detected between both configurations from the point of view of pressure ratio. Only in the case of the lowest engine speed (1000 rpm) and T\#2 (Figure 13), some improvements are obtained.
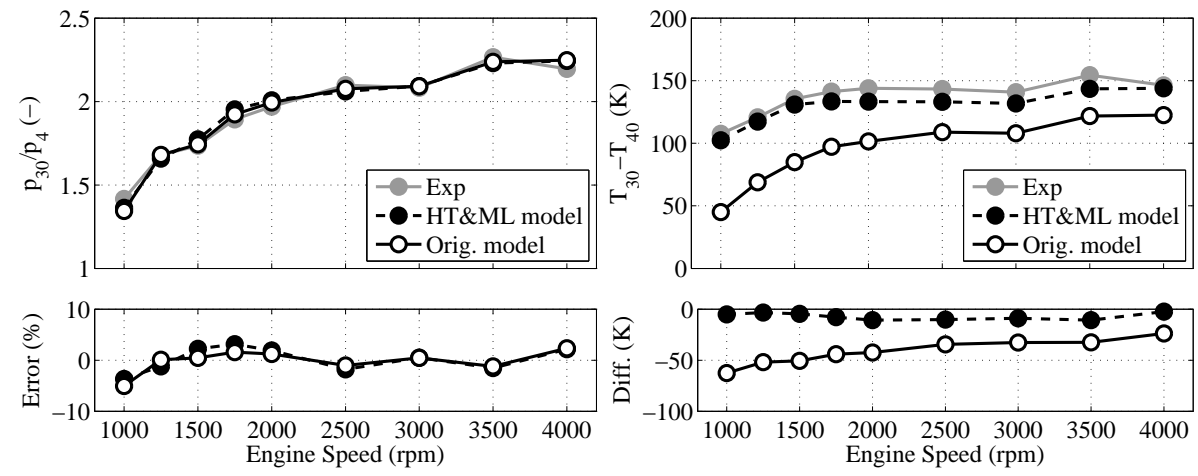

(a) Pressure ratio

(b) Turbine $\Delta T$

Figure 12: T\#1 Turbine pressure ratio and temperature drop

The most significant differences between both models appear in temperatures. Supplier turbine map, used by GT-Power includes the effect of the heat transfer and the mechanical losses as has been shown in Equation 3. This allows the accurate prediction of the turbine power only if the turbine inlet conditions are equal to those used to measure the map. On the contrary, HT\&ML model calculates the heat transfer and mechanical losses for every simulated engine conditions, for that reason it uses an adiabatic map where the efficiency, expressed in Equation 6, represents only the internal irreversibilities in the turbine flow. The heat $\left(\dot{Q}_{G A S / T}\right)$ is extracted from the gas before it is expanded in the turbine stator (see Figure 2 and Figure 14). Additionally, the turbocharger 


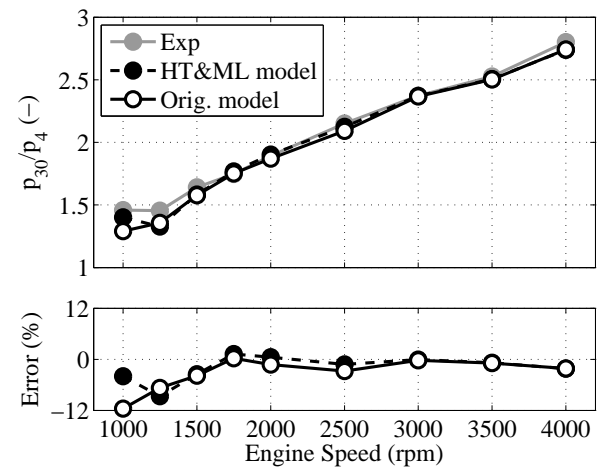

(a) Pressure ratio
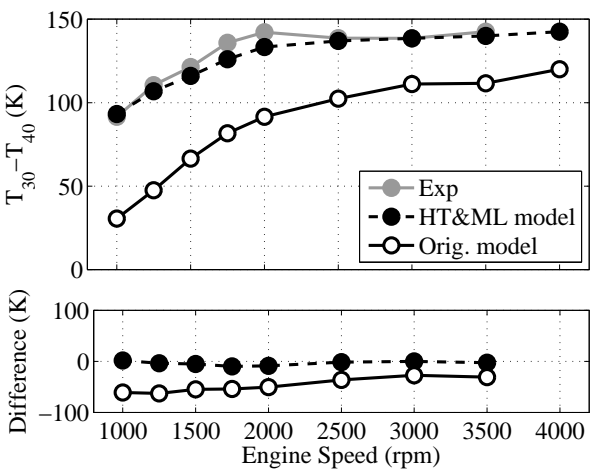

(b) Turbine $\Delta T$

Figure 13: T\#2 Turbine pressure ratio and temperature drop

mechanical loses are removed directly in the shaft.

$$
\eta_{t, a d i a b .}=\frac{T_{30 a}-T_{4 a}}{T_{30 a}-T_{4 a s}}=\frac{\dot{W}_{t}}{\dot{W}_{t s a}}
$$

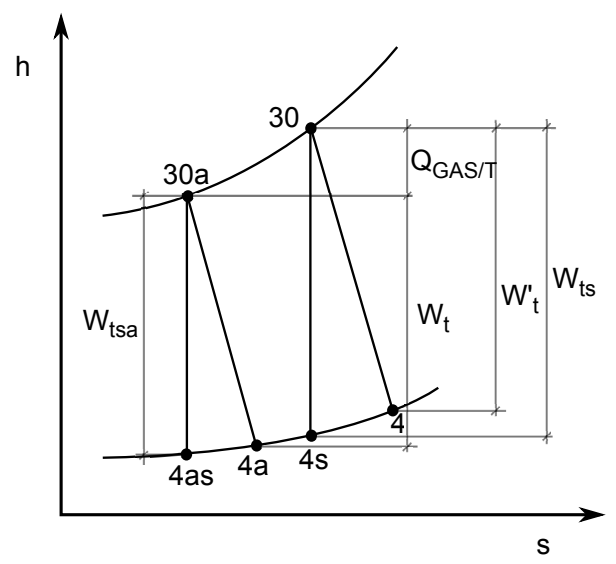

Figure 14: Enthalpy-entropy chart of the expansion process

In both simulation sets, the predicted turbine inlet temperature shows similar values due to the fact that this parameter is almost independent of the model used as it has been explained in section 3.2 . The most important difference is observed in turbine outlet temperature. Figure $12 \mathrm{~b}$ and Figure $13 \mathrm{~b}$ 

tion 4 can be provided by the HT\&ML model and it compares mechanical compressor power versus isentropic compressor power. On the other hand, the diabatic efficiency can obtained from the temperature drops in the compressor 


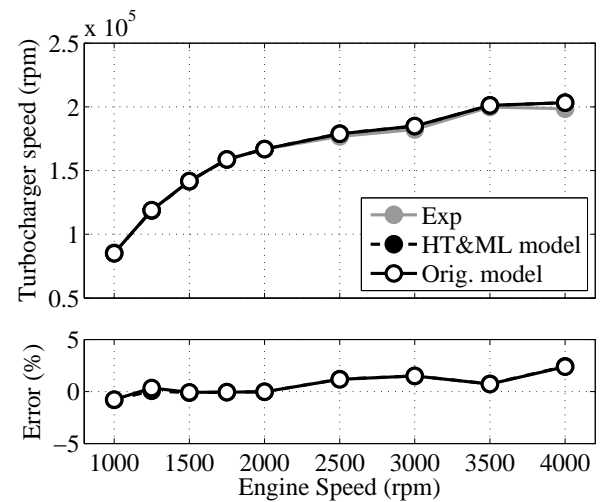

(a) $\mathrm{T} \# 1$
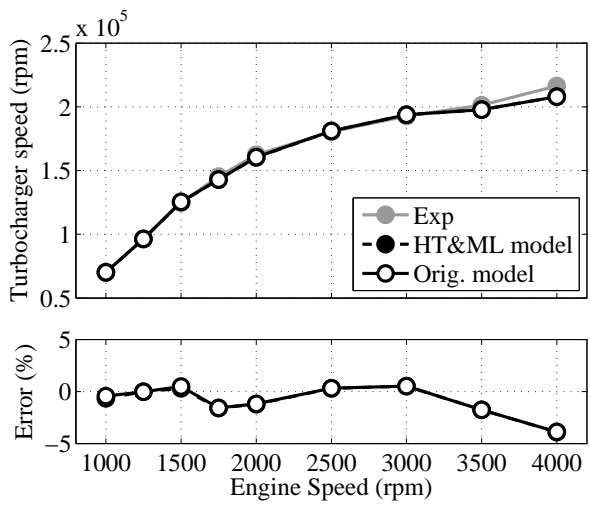

(b) $\mathrm{T} \# 2$

Figure 15: T\#1 and T\#2 turbocharger speed

and it includes the effect of the heat transfer. It must be taken into account that the powers are instantaneous variables obtained as a result of a non-linear calculation and the temperatures are weighted with instantaneous mass flow as shown in Equation 7

$$
\eta_{c, d i a b .}^{\text {model }}=\frac{\sum \dot{W}_{c s}^{i}}{\sum \dot{W}_{c}^{i}}=\frac{\sum \dot{m}_{c}^{i} \cdot \Delta T_{s}^{i}}{\sum \dot{m}_{c}^{i} \cdot \Delta T^{i}}
$$

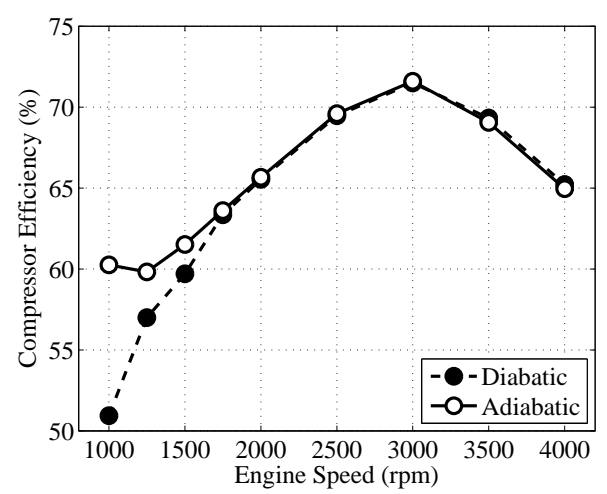

(a) $\mathrm{T} \# 1$

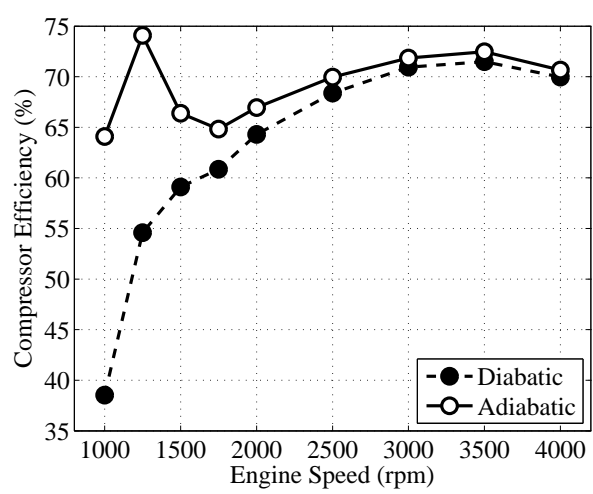

(b) $\mathrm{T} \# 2$

Figure 16: T\#1 and T\#2 compressor efficiency

Using $\mathrm{T} \# 1$, which is water cooled, both compressor efficiencies are very sim- 

important compared to turbine power the diabatic efficiency does not represent the actual aerodynamic efficiency of the turbine. 


$$
\begin{aligned}
\eta_{t, a d i a b .}^{\text {model }} \cdot \eta_{\text {mech }}^{\text {model }} & =\frac{\dot{W}_{t}}{\dot{W}_{t s a}} \frac{\dot{W}_{c}}{\dot{W}_{t}}=\frac{\dot{W}_{c}}{\dot{W}_{t s a}}=\frac{\sum \dot{m}_{t}^{i} \cdot c_{p, c}^{i} \cdot\left(T_{20 a}-T_{10}\right)^{i}}{\sum \dot{m}_{c}^{i} \cdot c_{p, t}^{i} \cdot\left(T_{30 a}-T_{4 a s}\right)^{i}} \\
\eta_{t, \text { diab. }}^{\text {model }} & =\frac{\sum \dot{m}_{t}^{i} \cdot\left(T_{30}-T_{4 a}\right)^{i}}{\sum \dot{m}_{t}^{i} \cdot\left(T_{30}-T_{4 s}\right)^{i}}=\frac{\dot{W}_{t}+\dot{Q}_{G A S / T}}{\dot{W}_{t s}}
\end{aligned}
$$

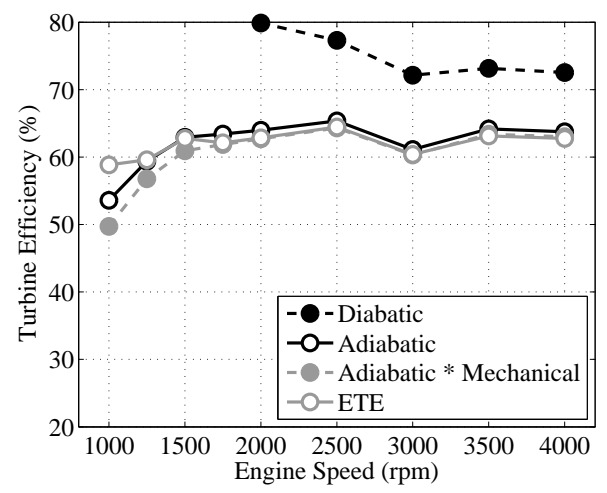

(a) $\mathrm{T} \# 1$

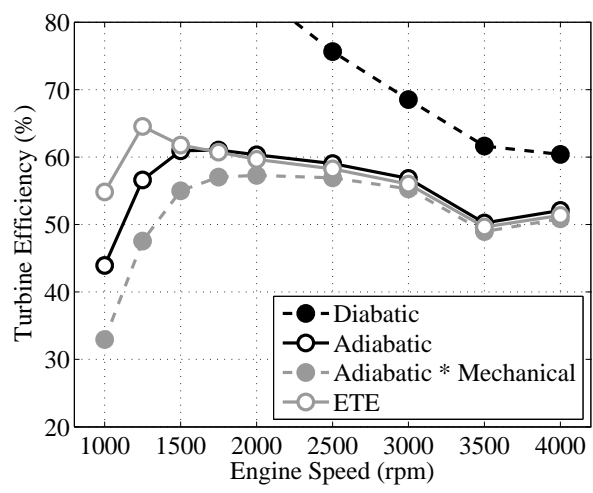

(b) $\mathrm{T} \# 2$

Figure 17: T\#1 and T\#2 turbine efficiency

Figure 17 compares the four turbine efficiencies for the full load engine tests, moved. It shows that diabatic efficiency is very high (in some cases higher than one), the reason is the lower turbine outlet temperature caused by the heat transfer in the turbine. This effect is more noticeable at lower speeds because turbine heat losses are higher, in relative terms, compared to turbine power. (Equation 8) represents the turbocharger friction losses, and hence the adiabatic efficiency is always higher. In general, the effect of the friction losses in the turbocharger is more important at low engine speed (i.e. low turbocharger speeds). Comparing ETE (Equation 3p with the product of adiabatic and mechanical efficiencies (Equation 8), the differences are caused by the inclusion of the heat in the compressor $\left(\dot{Q}_{C / A i r}\right)$ and the different turbine isentropic power 
used in both definitions $\left(\dot{W}_{t s a}\right.$ or $\left.\dot{W}_{t s}\right)$. As can be observed the differences between these two definitions are more important when the turbocharger is not water-cooled ( $\mathrm{T} \# 2)$, what increases the transfer of heat power from bearing housing to the compressor. In the case of $\mathrm{T} \# 1$, due to water cooling, only at $1000 \mathrm{rpm}$ appears a big difference between the three definitions.

Finally, an important parameter to analyse is turbocharger efficiency because of its influence on engine performance. If HT\&ML is used, the turbocharger efficiency is calculated according to Equation 10, while for simulations without HT\&ML, this efficiency is given by Equation 11. In the first case, an adiabatic map is used to compute turbocharger efficiency, whereas, in the second case, a hot map is used for the purpose. For both of these parameters, the calculations of the values from the models are obtained averaging the pulsating power.

$$
\begin{aligned}
& \eta_{T G, \text { adiab. }}^{\text {model }}=\eta_{t, \text { adiab. }}^{\text {model }} \cdot \eta_{c, \text { adiab. }}^{\text {model }} \cdot \eta_{\text {mech }}^{\text {model }}=\frac{\dot{W}_{t}}{\dot{W}_{t s a}} \frac{\dot{W}_{c s}}{\dot{W}_{c}} \frac{\dot{W}_{c}}{\dot{W}_{t}}=\frac{\dot{W}_{c s}}{\dot{W}_{t s a}} \\
& \eta_{T G, \text { map }}^{\text {model }}=E T E \cdot \eta_{c, \text { diab. }}^{\text {model }}=\frac{\dot{W}_{c}+\dot{Q}_{C / A i r}}{\dot{W}_{t s}} \frac{\dot{W}_{c s}}{\dot{W}_{c}+\dot{Q}_{C / A i r}}=\frac{\dot{W}_{c s}}{\dot{W}_{t s}}
\end{aligned}
$$

It is worth noting that the simplification given in Equation 11 is possible only 11) is low at high engine speeds. 


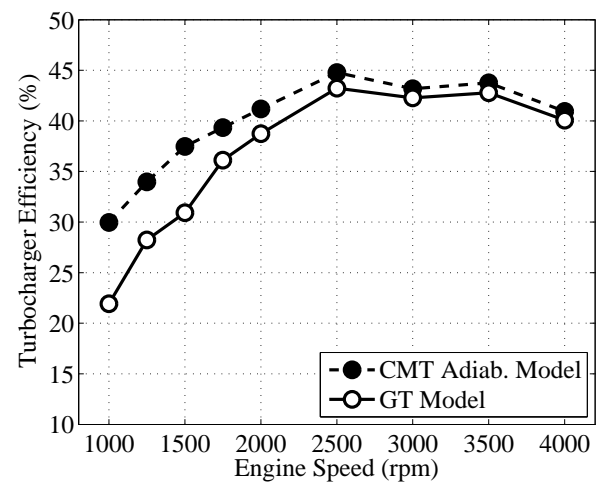

(a) $\mathrm{T} \# 1$

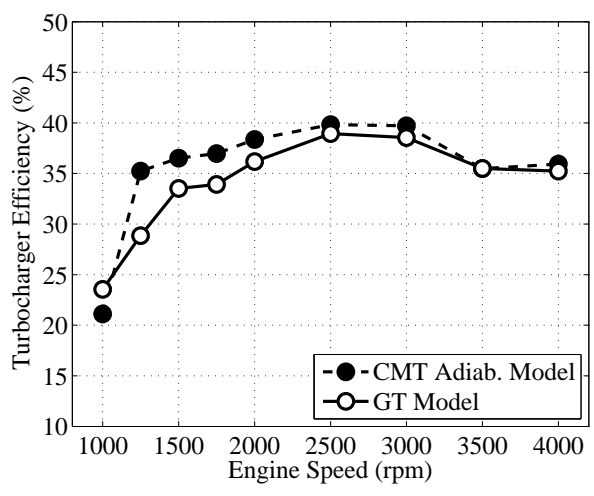

(b) $\mathrm{T} \# 2$

Figure 18: T\#1 and T\#2 turbocharger efficiency

When the turbocharger is working on the engine, heat and mechanical energy is transferred between the different elements. Using the information provided by the model, energy balances in the turbocharger can be computed from the point of view of heat power exchanged.

Figure 19 represents this heat balance for all full load working points. For T\#2 (Figure 19b the comparison is easier since, in this case, only the turbine losses heat. This behaviour occurs when the compressor just absorb the heat coming from the turbine. For the oil it is a predictable behaviour as it works as a heat sink in the absence of water cooling. For the compressor the sign of heat flow depends on the operating conditions.

At high pressure ratios, the compressor can lose heat that will be absorbed by the oil, ambient or the water (as shown in Figure $19 \mathrm{a}$ for $\mathrm{T} \# 1$ when the engine is running at $3500 \mathrm{rpm}$ and $4000 \mathrm{rpm}$ ). Figure $19 \mathrm{~b}$ also shows how the heat is distributed in $\mathrm{T} \# 2$. More than $50 \%$ of the heat losses in the turbine go to the ambient and this percentage increases at higher engine speeds. This result extracted from the HT\&ML model is in concordance with different studies of other authors such as [30]. The compressor receives similar heat power for all engine speeds in absolute value only slightly higher at low engine speeds. Nevertheless, this heat in relative terms and at high engine speed is negligible 


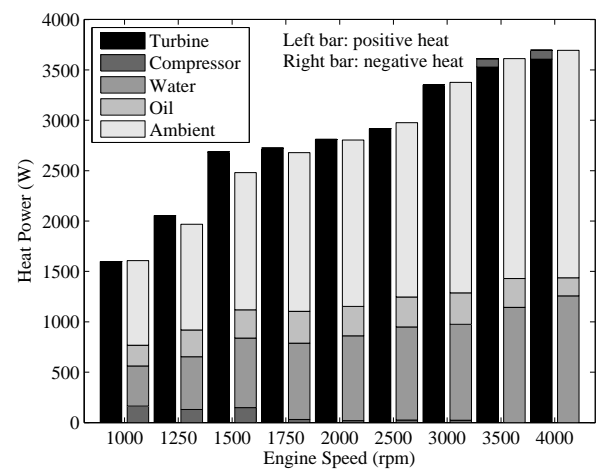

(a) $\mathrm{T} \# 1$

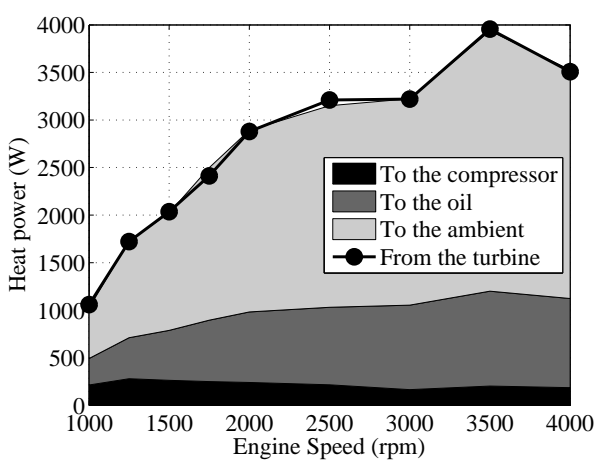

(b) T\#2

Figure 19: T\#1 and $\mathrm{T} \# 2$ heat power balance

in comparison to compressor power. In Figure $19 \mathrm{a}$ for $\mathrm{T} \# 1$, each engine test is represented by two different bars. The left bar is the sum of all heats flowing to the metal parts of the turbocharger and right bar is the sum of all heats flowing from the metal parts. In this case, turbine casing always losses heat power that is always received it by the ambient, the water and the oil. However, the heat flow in the compressor can change its direction (from/to central housing) depending on the operating conditions, as has been stated previously. In this case the ambient is again the node that receives a higher rate of heat and the oil receive low heat quantity due to the water-cooling. However, the compressor air at the engine speeds of $3500 \mathrm{rpm}$ and $4000 \mathrm{rpm}$ losses heat (positive sign) since it works with high pressure ratios, while at lower engine speeds (i.e. lower pressure ratios) the compressor air receives heat (negative sign).

Using the HT\&ML a turbocharger mechanical power balance can be also performed. Figure 20 represents this balance where a logarithmic y-axis has been used to remark the different orders of magnitude among turbine and compressor mechanical powers and turbocharger friction losses power. As can be observed in Figure 20 despite the fact that the mechanical losses are higher at high engine speed tests, the effect of these losses is much more important at low engine speed points because compressor and turbine power decrease faster than mechanical 
losses at low engine speeds.

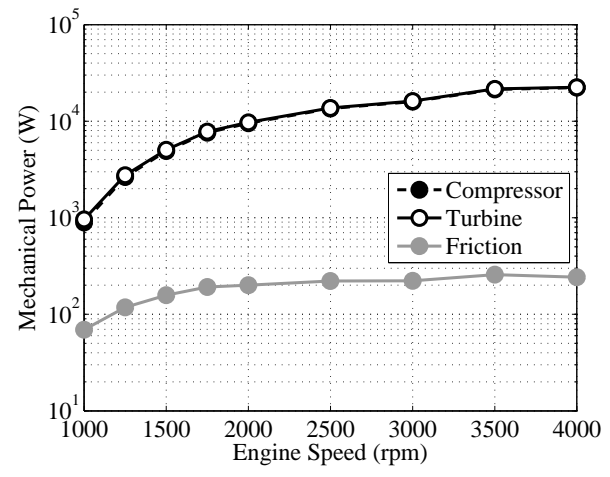

(a) $\mathrm{T} \# 1$

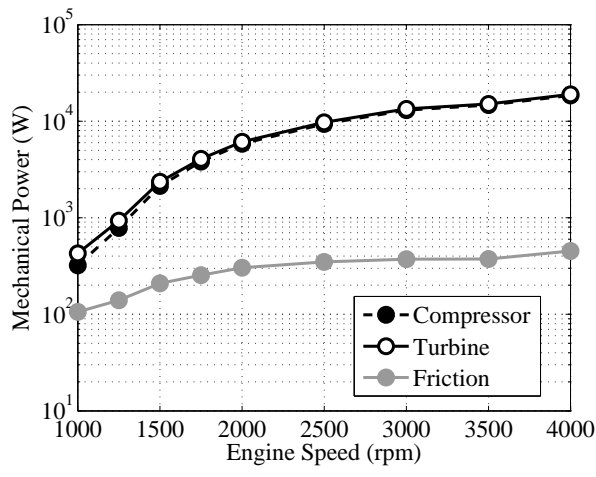

(b) $\mathrm{T} \# 2$

Figure 20: T\#1 and T\#2 mechanical power balance

\section{Discussion of results}

The comparison between the results of both kind of simulations and the experimental data shows that COT and TOT prediction is the main substantial improvement using a heat transfer and mechanical losses model for the turbocharger. This improvement is crucial in inter-cooling [31, combustion process [32] where there is no intercooler, aftertreatment [33], exhaust energy recovery [34, exhaust heat transfer modelling [35] and two stage turbocharging [36] modelling. Even the simulation of full load conditions can be improved using HT\&ML model. However, the improvements of the model result only in the prediction of COT and TOT and do not affect the engine performance variables if the turbocharger map, used in the original configuration, is chosen properly. This map must have been measured in similar conditions to those desired to be modelled, so turbocharger manufacturer maps that hold this condition are suitable to be used in order to predict well all the variables associated to the engine excepting TOT. Cold maps can also be used but always coupled with a HT\&ML model. In that case the prediction of all variables, including TOT is precise. The turbo speed is not affected by the different models as it has been shown in this 
work and it has been demonstrated by the development shown in Equations 12 . 13 and 14 showing turbocharger speed increment, where $K$ primarily depends on turbocharger shaft inertia and time step. Previously in Equation 12 ETE definition is derived; where the compressor mechanical power has been replaced by the product of mechanical efficiency and turbine mechanical power. Since the only difference between $\dot{W}_{t s}$ and $\dot{W}_{t s a}$ is the turbine inlet temperature, it 470 is possible to introduce turbine adiabatic efficiency in the equation as has been done in Equation 12 .

$$
E T E=\frac{\eta_{\text {mech }} \cdot \dot{W}_{t}+\dot{Q}_{C / \text { Air }}}{\dot{W}_{t s}}=\left(\eta_{\text {mech }} \cdot \eta_{t, \text { adiab. }}+\frac{\dot{Q}_{C / A i r}}{\dot{W}_{t s a}}\right) \frac{T_{30 a}}{T_{30}}
$$

In Equation 13 the turbo speed increment expression has been derived using the HT\&ML model approach. The resulting equation is function of compressor and turbine adiabatic efficiencies, turbocharger friction losses efficiency and isentropic power of compressor and turbine.

$$
\begin{aligned}
\Delta N & =K\left(\dot{W}_{t}-\dot{W}_{\text {mech }}-\dot{W}_{c}\right)= \\
& =K\left(\eta_{\text {mech }} \cdot \dot{W}_{t}-\dot{W}_{c}\right)= \\
& =K\left(\eta_{\text {mech }} \cdot \eta_{t, \text { adiab. }} \cdot \dot{W}_{t s a}-\frac{\dot{W}_{c s}}{\eta_{c, \text { adiab. }}}\right)
\end{aligned}
$$

In Equation 14 the turbo speed increment expression has been derived using the original model approach, i.e using map efficiencies definitions (ETE and $\left.\eta_{c, \text { diab. }}\right)$. Introducing Equations 5 and 12 and it gives the same expression as in Equation 13

$$
\begin{aligned}
\Delta N & =K\left(\dot{W}_{t}^{\prime}-\dot{W}_{c}^{\prime}\right)= \\
& =K\left(E T E \cdot \dot{W}_{t s}-\frac{\dot{W}_{c s}}{\eta_{c, d i a b .}}\right)= \\
& =K\left(E T E \cdot \frac{T_{30}}{T_{30 a}} \cdot \dot{W}_{t s a}-\frac{\dot{W}_{c s}}{\eta_{c, d i a b .}}\right)=
\end{aligned}
$$




$$
\begin{aligned}
& =K\left(\eta_{\text {mech }} \cdot \eta_{t, \text { adiab. }} \cdot \dot{W}_{t s a}+\dot{Q}_{C / \text { Air }}-\frac{\dot{W}_{c s}}{\eta_{c, \text { diab. }}}\right)= \\
& =K\left(\eta_{\text {mech }} \cdot \eta_{t, \text { adiab. }} \cdot \dot{W}_{t s a}+\dot{Q}_{C / \text { Air }}-\left(\dot{W}_{c}+\dot{Q}_{C / \text { Air }}\right)\right)= \\
& =K\left(\eta_{\text {mech }} \cdot \eta_{t, \text { adiab. }} \cdot \dot{W}_{t s a}-\frac{\dot{W}_{c s}}{\eta_{c, \text { adiab. }}}\right)
\end{aligned}
$$
these phenomena. The compressor and turbine outlet temperatures are important variables to be predicted at these operating points. The importance is in 
intercooler design (or combustion process), aftertreatment, exhaust energy re-

predicted boundary conditions can be used in each case.

Besides, the paper shows that turbo speed prediction is not affected by heat transfer when hot turbocharger maps in which compressor and turbine have been measured at the same time are used. The reason is the cancellation of compressor heat terms in this kind of maps. Only prediction of compressor and turbine outlet temperatures is improved by the heat transfer model, if they are compared to the model based on hot maps.

Finally, it has been shown that the information provided by the model can be used to perform turbocharger energy balances that shows the more important energy losses in the turbocharger as a function of engine speed.

\section{Acknowledgements}

This work has been financial supported by Jaguar Land Rover Ltd. It has been also partially supported by Ministerio de Economía y Competitividad, Secretaría de Estado de Investigación, Subdirección de proyectos de investigación ${ }_{520}$ (TRA2013-40853-R).

\section{References}

[1] N. Baines, Intake Boosting, Encyclopedia of Automotive Engineering, John Wiley \& Sons, Ltd., 2014. doi:/10.1002/9781118354179.auto126

[2] L. Cornolti, A. Onorati, T. Cerri, G. Montenegro, F. Piscaglia, 1D simulation of a turbocharged Diesel engine with comparison of short and

口 long EGR route solutions, Applied Energy 111 (2013) 1 - 15. doi: /10.1016/j.apenergy.2013.04.016

[3] S. Marelli, C. Carraro, G. Marmorato, G. Zamboni, M. Capobianco, Experimental analysis on the performance of a turbocharger compressor in 
[9] H. Aghaali, H.-E. Ångström, Turbocharged SI-Engine Simulation with Cold and Hot-Measured Turbocharger Performance Maps, in: Proceedings of

the unstable operating region and close to the surge limit, Experimental Thermal and Fluid Science 53 (2014) 154 - 160. doi:/10.1016/j. expthermflusci.2013.11.025.

[4] B. Sirakov, M. Casey, Evaluation of heat transfer effects on turbocharger performance, ASME Journal of Turbomachinery 135 (2) (2012) 021011. doi:/10.1115/1.4006608,

[5] A. Romagnoli, R. Martinez-Botas, Heat transfer analysis in a turbocharger turbine: An experimental and computational evaluation, Applied Thermal Engineering 38 (2012) 58 - 77. doi:/10.1016/j.applthermaleng. 2011. 12.022

[6] M. V. Casey, T. M. Fesich, The efficiency of turbocharger compressors with diabatic flows, Journal of Engineering for Gas Turbines and Power 132 (7) (2012) 072302. doi:/10.1115/1.4000300

[7] H. Aghaali, H.-E. Ångström, J. R. Serrano, Evaluation of different heat transfer conditions on an automotive turbocharger, International Journal of Engine Research 16 (2) (2015) 137-151. doi:/10.1177/ 1468087414524755 .

[8] K. Chapman, R. Nguru, J. Shultz, Simplified Methodology to Correct Turbocharger Field Measurements for Heat Transfer and Other Effects: Topical Report, January 2000 - June 2002, Report: Gas Research Institute, Kansas State University, 2002.

ASME Turbo Expo, Vol. 5, ASME, 2012, pp. 671-679. doi:10.1115/ GT2012-68758.

[10] P. Chesse, D. Chalet, X. Tauzia, Impact of the heat transfer on the performance calculations of automotive turbocharger compressor, Oil \& Gas 
Science and Technology - Rev. IFP Energies nouvelles 66 (5) (2011) 791 800. doi:10.2516/ogst/2011129.

[11] R. D. Burke, C. R. M. Vagg, D. Chalet, P. Chesse, Heat transfer in turbocharger turbines under steady, pulsating and transient conditions, International Journal of Heat and Fluid Flow 52 (0) (2015) 185 - 197. doi:/10.1016/j.ijheatfluidflow.2015.01.004

[12] A. Romagnoli, R. Martinez-Botas, Heat transfer in an automotive turbocharger under constant load points: an experimental and computational investigation, The 4th International Symposium on Fluid Machinery and Fluid Engineering November 24-27, 2008, Beijing, China.

[13] R. D. Burke, C. D. Copeland, T. Duda, Investigation into the assumptions for lumped capacitance modelling of turbocharger heat transfer, in: 6th International conference on simulation and testing 2014-05-15 - 2014-0516, Berlin, 2014.

[14] H. Aghaali, H.-E. Ångström, Temperature estimation of turbocharger working fluids and walls under different engine loads and heat transfer conditions, SAE Technical Paper 2013-24-0123. doi:/710.4271/ 2013-24-0123.

[15] Evaluation of measurement data - Guide to the expression of uncertainty in measurement, JCGM.

[16] P. Olmeda, A. Tiseira, V. Dolz, L. García-Cuevas, Uncertainties in power computations in a turbocharger test bench, Measurement 59 (0) (2015) 363 -371. doi:http://dx.doi.org/10.1016/j.measurement.2014.09.055.

[17] F. Payri, A. J. Torregrosa, A. Broatch, J. Brunel, Pressure loss characterisation of perforated ducts, SAE Technical Paper 980282. doi: $/ 10.4271 / 980282$. 
[18] F. Payri, P. Olmeda, J. Martín, A. García, A complete 0D thermodynamic predictive model for direct injection diesel engines, Applied Energy 88 (12) (2011) 4632 - 4641. doi:/10.1016/j.apenergy.2011.06.005

[19] J. Benajes, P. Olmeda, J. Martín, R. Carreño, A new methodology for uncertainties characterization in combustion diagnosis and thermodynamic modelling, Applied Thermal Engineering 71 (1) (2014) 389 - 399. doi: $/ 10.1016 / \mathrm{j}$.applthermaleng.2014.07.010

[20] P. Olmeda, V. Dolz, F. Arnau, M. Reyes-Belmonte, Determination of heat flows inside turbochargers by means of a one dimensional lumped model,

【 Mathematical and Computer Modelling 57 (7-8) (2013) 1847 - 1852. doi: $/ 10.1016 / \mathrm{j} . \mathrm{mcm} .2011 .11 .078$.

[21] A. J. Torregrosa, A. Broatch, P. Olmeda, J. Martín, A contribution to film coefficient estimation in piston cooling galleries, Experimental Thermal and Fluid Science 34 (2) (2010) 142-151.

[22] J. R. Serrano, P. Olmeda, A. Páez, F. Vidal, An experimental procedure to determine heat transfer properties of turbochargers, Measurement Science and Technology 21 (2010) 035109. doi:/10.1088/0957-0233/21/3/ 035109

[23] M. Reyes-Belmonte, Contribution to the experimental characterization and 1-D modelling of turbochargers for IC engines, Ph.D. thesis, Universitat Politècnica de València, Valencia (2013).

[24] F. Payri, P. Olmeda, F. Arnau, A. Dombrovsky, L. Smith, External heat losses in small turbochargers: Model and experiments, Energy 71 (2014) 534 - 546. doi:/10.1016/j.energy.2014.04.096.

[25] J. R. Serrano, P. Olmeda, A. Tiseira, L. García-Cuevas, A. Lefebvre, Theoretical and experimental study of mechanical losses in automotive turbochargers, Energy 55 (2013) 888 - 898. doi:10.1016/j.energy.2013. 04.042 
[26] J. R. Serrano, P. Olmeda, F. Arnau, A. Dombrovsky, L. Smith, Analysis and methodology to characterize heat transfer phenomena in automotive turbochargers, J. Eng. Gas Turbines Power 137 (7) (2014) 021901 (11 pages) Paper No: GTP-14-1352. doi:/10.1115/1.4028261.

[33] J. M. Luján, V. Bermúdez, P. Piqueras, Óscar García-Afonso, Experimental assessment of pre-turbo aftertreatment configurations in a single stage turbocharged diesel engine. part 1: Steady-state operation, Energy 80 (0) 
[34] V. Macián, J. R. Serrano, V. Dolz, J. Sánchez, Methodology to design a bottoming Rankine cycle, as a waste energy recovering system in vehicles. Study in a HDD engine, Applied Energy 104 (2013) 758 - 771. doi:/10. 1016/j.apenergy.2012.11.075.

${ }_{645}$ [35] J. M. Luján, H. Climent, P. Olmeda, V. D. Jiménez, Heat transfer modeling in exhaust systems of high-performance two-stroke engines, Ap-

a plied Thermal Engineering 69 (1-2) (2014) 96 - 104. doi:/10.1016/j. applthermaleng.2014.04.045.

[36] J. Galindo, J. R. Serrano, H. Climent, O. Varnier, Impact of two-stage turbocharging architectures on pumping losses of automotive engines based on an analytical model, Energy Conversion and Management 51 (10) (2010) 1958 - 1969. doi:/10.1016/j.enconman.2010.02.028. 